\title{
INICIO DE LA TENTATIVA Y OPORTUNIDAD-PARA-LA-ACCIÓN
}

ATTEMPT'S BEGIN AND OPPORTUNITY-FOR-ACTION

\author{
Juan Pablo Mañalich R.
}

RESUMEN: El artículo ofrece una reformulación del criterio de la acción intermedia, o de la “inmediatez-de-acción”, para el reconocimiento del inicio de una tentativa (inacabada). Sobre la base de una clarificación de las condiciones de adecuación dogmática que ha de satisfacer la formulación de semejante criterio, este es reconstruido en el sentido del modelo de la oportunidad-para-la-acción. El artículo se cierra con una indagación en la relevancia de la así llamada "suerte circunstancial" para la demarcación entre preparación y tentativa.

Palabras clave: tentativa, acción intermedia, oportunidad para la acción, suerte circunstancial.

ABSTRACT: The paper offers a reformulation of the criterion of intermediate-action, or of "action-immediacy", for fixing the point in which an (incomplete) attempt begins to take place. Upon a clarification of the conditions of doctrinal adequacy that its formulation must satisfy, the criterion is reconstructed in the sense of a model of action-opportunity. The article closes with an inquiry into the relevance of so called "circumstantial luck" for the demarcation of preparation and attempt.

Key words: attempt, intermediate action, action-opportunity, circumstantial luck.

\section{INTRODUCCIÓN: EL INICIO DE LA TENTATIVA COMO CATEGORÍA DE LA TENTATIVA INACABADA}

Bajo un sistema jurídico que, como el chileno, diferencia los regímenes de punibilidad y penalidad de la tentativa acabada y la tentativa inacabada ${ }^{1}$, el problema del inicio de la tentativa, que Bockelmann caracterizara como el "más difícil [de] la dogmática de la tentativa", sistemáticamente pertenece a la segunda de aquellas dos categorías ${ }^{2}$. Esta afirmación encuentra sustento inmediato en el modelo teórico que será brevemente reseñado en lo que sigue ${ }^{3}$.

La imperfección delictiva que es definitoria de toda tentativa de delito se explica por el hecho de que el comportamiento constitutivo de tal resulta imputable bajo una descrip-

\footnotetext{
Doctor en derecho, Universidad de Bonn; profesor titular, Departamento de Ciencias Penales, Facultad de Derecho, Universidad de Chile. Dirección postal: Av. Santa María 076, 7520405, Providencia. Dirección electrónica: jpmanalich@derecho.uchile.cl. El presente artículo ha sido elaborado en el marco del Proyecto Fondecyt No 1160147 (regular), del cual el autor es investigador responsable. Agradezco a Isabel Yáñez M., ayudante ad honorem, por su colaboración en la revisión del texto.

1 Diferenciación que el CP chileno asocia a la distinción entre las nociones de "delito frustrado" y "tentativa" (a secas), respectivamente, en los términos de su art. $7^{\circ}$.

2 Bockelmann (1957) p. 134.

3 Véase Mañalich (2017a) pp. 462 ss., 475 ss.
} 
ción que determina su falta de antinormatividad bajo la norma cuyo quebrantamiento se identifica con esa misma tentativa. Que un comportamiento que no resulta antinormativo bajo una determinada norma pueda, no obstante, resultar imputable como quebrantamiento de esa misma norma, se explica por la irreductible incertidumbre que define la situación del destinatario de la norma acerca de si la acción que se encuentra en posición de omitir o ejecutar llegará a satisfacer, ex post, la descripción bajo la cual esa acción ejemplificaría el tipo de acción sometido a prohibición o requerimiento, según corresponda. Con arreglo a la creencia predictiva que aquel puede formarse en cuanto a las propiedades (basales) que habría de llegar a exhibir su comportamiento, la norma en cuestión puede fundamentar un concreto deber -esto es, la necesidad práctica- de omitir o ejecutar una acción particular, aun cuando el comportamiento a través del cual tiene lugar la infracción de ese deber no necesariamente haya de resultar antinormativo.

Desde este punto de vista, la diferencia entre una tentativa acabada y una tentativa inacabada se reduce a que en la primera el comportamiento efectivamente desplegado por el destinatario de la norma es suficiente para constituirse, con cargo a la respectiva creencia predictiva, como la infracción de un deber fundamentado por la norma. En la tentativa inacabada, por el contrario, el comportamiento del agente por sí mismo no alcanza, con cargo a esa misma creencia, a servir de vehículo a la declaración de que la norma respectiva no resulta reconocida como premisa vinculante. Estructuralmente, este déficit resulta compensado a través de la así llamada "resolución-al-hecho". Por tal cabe entender una intención ("previa") de ejecutar u omitir una acción que, bajo la creencia predictiva en cuestión, el agente tendría que omitir o ejecutar para así adecuar su comportamiento a la norma, sin que la descripción que especifica la acción a cuya ejecución u omisión se encuentra referida la intención en cuestión necesite coincidir con la descripción bajo la cual tal acción resulta prohibida o requerida por la norma ${ }^{4}$.

Que la adscripción de tal resolución-al-hecho puede proveer el criterio de compensación requerido, se sigue de que el agente que se forma semejante intención previa adquiere, de ese modo, un determinado compromiso práctico, que sustenta la expectativa de que él en efecto llegue a realizar esa misma intención, ejecutando u omitiendo la acción respectiva cuando bajo su representación de las circunstancias se configure la correspondiente "oportunidad-para-la-acción”. Puesto que su función consiste en compensar un déficit exclusivamente exhibido por la tentativa inacabada, la categoría de la resolución-al-hecho es privativa de esta forma de tentativa. Con ello, si el inicio de la tentativa se corresponde con el momento en el cual la intención en cuestión ha de verse actualizada como resolución-al-hecho, entonces la categoría del inicio de la tentativa también es exclusiva de la tentativa inacabada 5 .

\footnotetext{
4 En detalle, Mañalich (2019b) III.

5 En esta dirección ya KüHL (1980) p. 125. Una fundada refutación de la propuesta de definición general del concepto de tentativa de delito a partir de la noción de "principio de la ejecución" (Anfang der Ausführung), en inmediata referencia al tenor del antiguo $\S 43$ del StGB, fue ofrecida por CoHN (1880) pp. 17 ss., aun cuando sobre la base de una problemática validación de la distinción entre "delitos materiales" y "delitos formales".
} 


\section{EL INICIO DE LA TENTATIVA BAJO EL CRITERIO DE LA ACCIÓN INTERMEDIA}

\subsection{LA INADECUACIÓN DE LA SOLUCIÓN OBJETIVO-FORMAL}

$\mathrm{Al}$ interior del repertorio de propuestas tradicionalmente manejadas por la dogmática de la tentativa para articular la demarcación entre esta y el ámbito de la preparación ${ }^{6}$, el criterio de la acción intermedia parece ser el único que satisface presupuestos mínimos de adecuación explicativa. Para sustentar esta última afirmación basta con reseñar algunas de las contundentes objeciones esgrimidas contra las propuestas que rivalizan con ella.

Es usual que la ya referida demarcación se oriente a especificar las condiciones de cuya satisfacción depende que un comportamiento tenga el carácter de "acción ejecutiva" Bajo la así solución objetivo-formal, y según la formulación que a esta diera Robert Von Hippel, por tal habría que entender ni más ni menos que la acción típica, esto es, aquella que "cae bajo el tipo-de-delito", en cuanto acción que "corresponde in concreto al comportamiento allí en general puesto bajo pena" ${ }^{8}$. Pero esto no puede tomarse al pie de letra. Pues si se trata aquí de una propuesta de determinación de lo que ha de constituir el inicio de una tentativa, ella no puede pasar por alto que un comportamiento constitutivo de tentativa es uno que resulta imputable bajo una descripción distinta de aquella que lo convertiría en una instancia de realización (antijurídica) del tipo en cuestión ${ }^{9}$, esto es, en una instancia del correspondiente delito consumado ${ }^{10}$. De ahí que Von Hippel observara que la respectiva acción ejecutiva consistiría en "toda especie de acción de matar en el homicidio, el sustraer en el hurto, el engañar en la estafa, el exhortar en los delitos de exhortación, el amenazar en la coacción y la extorsión, el ejercicio de violencia en los delitos de violencia, el incendiar, el ejercicio de la caza, etc." ${ }^{\prime 1}$.

Es llamativo que Von Hippel no reparara en la heterogeneidad de los ejemplos por él aducidos. En sus propios términos, tal ejemplificación del concepto de acción ejecutiva fracasa sin más tratándose de delitos como el homicidio y el incendio. Pues tanto "matar" como "incendiar" son verbos que especifican tipos de acción definidos por la clase de resultado en cuya producción consiste el delito -en tal medida: "resultativo"- correspondiente ${ }^{12}$. Por ello, no tiene sentido sugerir que una acción pueda ser descrita como una instancia de matar (a otro ser humano nacido) o como una instancia de incendiar (algo), sin que esa acción realice, eo ipso, el tipo del homicidio o del incendio ${ }^{13}$. La misma dificultad no se

\footnotetext{
${ }^{6}$ En general al respecto, y desde una crítica del modelo del iter criminis, véase Mañalich (2019b) II; sobre esto, véase ya FinCKE (1975) pp. 35 s. En referencia al problema en la tradición del common law, Duff (1996) pp. 33 ss.

7 Véase ya Von Hippel (1930) pp. 397 ss.

8 Von Hippel (1930) p. 398. En general sobre la solución objetivo-formal, véase BerZ (1984) p. 512; AlCáCER (2001) pp. 50 ss.

9 En detalle al respecto, Mañalich (2017a) pp. 467 ss.

10 Véase Von Hippel (1930) p. 396.

11 Von Hippel (1930) p. 398.

12 Tratándose del homicidio, ello depende, como es obvio, de que el complemento directo del verbo "matar" se corresponda con una expresión que haga referencia a un individuo (nacido) de la especie humana.

13 Véase, empero, Alcácer (2001) pp. 54 ss.
} 
suscita, verbigracia, tratándose de la estafa, cuyo tipo se ve realizado por la producción de un resultado distinto del resultado que define el tipo de acción especificado por el verbo "engañar"14. Y de ahí que sea respecto de delitos como la estafa o la coacción que la solución objetivo-formal muestre alguna plausibilidad. Para ello, una acción ejecutiva en el sentido de una posible tentativa de estafa, consistente en la materialización de un engaño con potencial relevancia para que otra persona lleve a efecto una disposición patrimonial perjudicial, tendría que poder ser identificada con una "realización parcial" del tipo de la estafa.

El problema está en que hablar de una "realización parcial del tipo" no tiene sentido. Para todo tipo-de-delito $T_{x}$ vale la proposición de que o bien $T_{x}$ se ha realizado o bien $T_{x}$ no se ha realizado: tertium non datur ${ }^{15}$. La posibilidad de descomponer analíticamente un tipo cualquiera en múltiples "elementos", alguno de los cuales pueda corresponderse con un verbo de acción, no autoriza a suponer que la satisfacción de uno o más de esos elementos, mas no de todos, daría lugar a una "realización parcial" del tipo en cuestión ${ }^{16}$. Pues esta jerga desconoce que la realización de todo tipo-de-delito, en cuanto relación de satisfacción semántica, queda sometida a un principio de indivisibilidad ${ }^{17}$.

Esta objeción subyace a la manera en que en la discusión alemana se impuso el rechazo de la solución objetivo-formal ${ }^{18}$. La cuestión ha quedado asociada a la decisión por la que el Tribunal Superior de Karlsruhe resolvió un caso en el que se había imputado una tentativa de estafa a una mujer que en la calle se habría aproximado a otra pretendiendo hacerle creer que ambas serían parientes, para así ganar su confianza y lograr acompañarla a su casa, donde le haría creer que había previamente sufrido un accidente para así conseguir que la otra mujer accediera a prestarle dinero ${ }^{19}$. El tribunal negó la existencia de una tentativa de estafa, esgrimiendo que la acción atribuida a la acusada, consistente en aparentar ser pariente de su potencial víctima, no era "la acción de engaño decisiva para el tipo de la estafa”. Pues esta última tendría que haber sido identificada, más bien, con el engaño que la acusada no llegó a materializar y por el cual esta perseguía obtener el préstamo de dinero.

\footnotetext{
14 Esto no quiere decir que el tipo de acción especificado a través del verbo "engañar" no quede definido por una determinada clase de resultado. En efecto, X solo engaña a Y si Y resulta engañado por X, esto es, si Y se forma una creencia falsa cuyo contenido proposicional se corresponda con el contenido proposicional de una afirmación (explícita o concluyentemente) realizada por X.

15 Véase ya Beling (1922) pp. 80 s., 84 ss., aun cuando (todavía) haciendo suya la distinción entre los conceptos de tentativa y de "falta de tipo" -véase en contra Belng (1930) p. 20-, para sobre tal base sustentar la tesis de la falta de relevancia jurídico-penal de la así llamada "tentativa absolutamente inidónea", definida por la falta de alguna de las "relaciones con el ambiente" (Millieubeziehungen) que debe exhibir el comportamiento típicamente relevante. Al respecto, Mañalich (2019a) pp. 322 ss. .

16 Véase Dold (2017) pp. 141 ss., quien muestra que el objeto de referencia del dolo debe entenderse constituido por circunstancias que realizan o realizarían el tipo, y no por circunstancias que acumulativamente realizarían cada uno de los múltiples elementos en que aquel pudiera descomponerse.

17 Véase ya Mañalich (2019a) pp. 300 ss.

18 Véase empero Maier (2005) pp. 209 ss., 219 ss., quien argumenta a favor de una determinación del inicio de la tentativa específicamente referida a cada tipo-de-delito, para así perfilar el correspondiente tipo-de-tentativa. Críticamente al respecto, SAFFerLing (2006) pp. 696 ss.

19 OLG Karlsruhe, decisión de 12 de agosto de 1981 - 3 Ss 167/81. Al respecto, Berz (1984) p. 512. Al respecto y detalladamente, Burkhardt (1983) pp. 427 ss., impugnando el "dogma de la realización parcial del tipo"; también KÜPER (1992) pp. 341 ss., 345 ss.
} 
Que en el caso aquí considerado era errado postular la existencia de una tentativa (inacabada) de estafa se sigue, en efecto, de que la respuesta a la pregunta de si lo hecho por alguien se deja describir como un eventual engaño es, por sí misma, criteriológicamente irrelevante para responder la pregunta de si el comportamiento en cuestión resulta constitutivo de una tentativa de estafa ${ }^{20}$. Pues el tipo de la estafa no consiste en una adición de elementos diversos, uno de los cuales es expresado por el verbo de acción "engañar", sino más bien -y como todo tipo-de-delito- en una descripción unitaria que especifica una forma de comportamiento que por esa vía adquiere relevancia jurídico-penal ${ }^{21}$. Precisamente por esto ya Beling proclamaba la estricta relatividad-al-tipo de la noción de "elemento constitutivo del tipo"22. Y para determinar si se configura una tentativa de un delito cualquiera no tiene sentido preguntar si el comportamiento atribuible al agente realiza, aisladamente, un determinado elemento del tipo del delito en cuestión ${ }^{23}$. Pues como ya se sugiriera, la realización de una parte -esto es, de algún elemento- del tipo no equivale a una pretendida realización parcial del tipo ${ }^{24}$.

Notablemente, Von Hippel advertía que el test de la realización parcial del tipo, si se lo administra de manera "puramente lógica", tendría que llevar a negar la existencia de una tentativa del delito respectivo en casos "en los cuales la acción se aproxima hasta el punto inmediatamente previo al límite de la ejecución” ${ }^{25}$. Lo contra-intuitivo de esta solución haría imprescindible flexibilizar el criterio por él previamente ofrecido, para así conferir relevancia a "la consideración unitaria del suceso histórico que concebimos y se despliega unitariamente" ${ }^{26}$. Esto llevaría, en la senda marcada por Frank ${ }^{27}$, a tener que reconocer ya un inicio de la ejecución en aquellas acciones "que en virtud de su co-correspondencia inmediata con la acción típica aparecen, para la concepción natural, como componentes de ella" 28 . Más adelante nos interesará volver sobre el llamado de atención de Von Hippel acerca del riesgo de una dilatación temporal y material del criterio de la inmediatez así esbozado ${ }^{29}$.

\footnotetext{
20 KÜPER (1992) pp. 346 s.

21 Véase Beling (1906) pp. 110 ss.

22 BeLING (1906) p. 291.

23 Acertadamente Küper (1992) p. 347. De ahí que la defensa de la relevancia criteriológica de la realización de un elemento del tipo, ofrecida por Vogler (1993) pp. 297 ss., y reproducida por Murmann (1999) pp. 13 ss., no pueda tenerse por exitosa. Pues precisamente al sostener que el engaño en el cual había incurrido la acusada no resultaba "específico-del-tipo", Vogler concede que la constatación de la relevancia típica de un comportamiento cualquiera no equivale a la constatación de que ese comportamiento satisfaga una multiplicidad de "elementos" aisladamente considerados.

24 Por ello Berz (1984) p. 512, en referencia al caso conocido por el tribunal de Karlsruhe, podía observar que bajo el $\S 22$ del StGB la existencia de una tentativa no depende de que el comportamiento del potencial autor consista en un disponerse inmediatamente a la realización "de un elemento del tipo", sino a la realización "del tipo (en su conjunto)".

25 Von Hippel (1930) p. 402.

26 Von Hippel (1930) p. 402.

27 Véase FrAnK (1931) p. 87, cuya célebre fórmula reza: "ha de encontrarse un inicio de la ejecución en todos aquellos actos [Tätigkeitsakte] que en virtud de su necesaria co-correspondencia con la acción del tipo para la concepción natural aparecen como sus componentes".

28 Von Hippel (1930) p. 402; al respecto, SAFFerLing (2006) p. 686

29 Véase Von Hippel (1930) p. 402.
} 


\subsection{APTITUd DE GENERALIZACIÓN COMO EXIGENCIA METODOLÓGICA}

La inadecuación de la solución objetivo-formal podría augurar mejores chances de éxito a propuestas que abogan por la vinculación directa de la determinación del inicio de la tentativa con el fundamento "material" de su punibilidad ${ }^{30}$. Paradigmática de esta estrategia es la así llamada "teoría de la peligrosidad", que como su denominación lo sugiere identifica el inicio de la tentativa con la creación de un peligro para el bien jurídico cuyo menoscabo es definitorio del injusto del delito (consumado) respectivo ${ }^{31}$. Más allá de la inviabilidad estructural que afecta, en sus diferentes versiones, a las concepciones que pretenden reconducir el fundamento general de la relevancia jurídico-penal de la tentativa a un juicio de peligrosidad ${ }^{32}$, aquí interesa destacar la ineptitud criteriológica de tal propuesta de determinación del inicio de la tentativa. Ello resulta de que, en pos de concretar el criterio así favorecido, el peligro cuya creación sería constitutiva del inicio de la tentativa correspondiente deba identificarse con un peligro concreto. Esto es problemático a lo menos por dos razones ${ }^{33}$.

En primer lugar, la noción de peligro concreto especifica una forma de acaso, definida por la circunstancia de una imposibilidad práctica del impedimento de la lesión del respectivo bien jurídico por parte de su titular o beneficiario ${ }^{34}$. Así entendida, sin embargo, la noción de peligro concreto es enteramente inadecuada para determinar el umbral a partir del cual al destinatario de la norma correspondiente puede imputarse un quebrantamiento (imperfecto) de esta, en atención a las circunstancias que él tuviera por existentes al momento de resolverse a ejecutar u omitir una cierta acción. Pues al igual que las nociones de lesión y de peligro abstracto, la noción de peligro concreto es una categoría concerniente a la finalidad de protección atribuible a la norma de comportamiento de cuyo posible quebrantamiento se trata, y no en cambio una categoría que incida en el esclarecimiento de las condiciones de imputación de tal quebrantamiento ${ }^{35}$.

Esto último resulta internamente conectado con una segunda objeción, que denuncia el déficit de generalización que aqueja a la solución "peligrosista". La identificación del inicio de la tentativa con la creación de un peligro concreto podría a lo sumo reclamar alguna plausibilidad estructural tratándose de la tentativa de un delito de lesión. Tratándose, en cambio, de un delito de peligro concreto, la realización de cuyo tipo dependerá -valga la redundancia- de la generación del respectivo peligro concreto, esta no podría al mismo

\footnotetext{
30 Véase el panorama doctrinal ofrecido por AlCÁCER (2001) pp. 24 ss.

31 Véase Von Hippel (1966) pp. 18 ss., 26 ss., aun cuando bajo una concepción extraordinariamente laxa de la noción aquí relevante de peligro.

$32 \mathrm{Al}$ respecto, MaÑalich (2019a) pp. 334 ss., 355 ss.

33 Véase ya Berz (1984) p. 513.

34 Fundamental, KindHÄUSER (1989) pp. 205 ss., 210 ss. Esta especificación de la noción de peligro concreto es divergente de la asumida por Berz, quien a su vez la toma de Horn, bajo la cual la imposibilidad de controlar el acaecimiento del desenlace lesivo tendría que ser juzgada desde el punto de vista del propio agente; véase BeRZ (1984) p. 513, quien sobre tal base impugna la adecuación del criterio así perfilado en razón de que un peligro concreto sería reconocible, más bien, con el acabamiento de la tentativa en cuestión. Esto último supondría, sin embargo, identificar la noción de tentativa acabada con aquello que Dold (2017) pp. 41 ss., 46 ss., denomina una "tentativa concluida", definida por la "renuncia (dolosa) al control sobre el peligro" por parte del autor.

35 Vogel (1993) pp. 229 ss.
} 
tiempo servir como criterio de reconocimiento del inicio de la tentativa de ese mismo delito $^{36}$. Y a fortiori, la misma dificultad se presentará tratándose del inicio de la tentativa de un delito de peligro abstracto: si para su consumación es irrelevante sin más la eventual generación de un peligro concreto, entonces parece difícil explicar que aquella sí pudiera tener relevancia para la constitución de una tentativa (inacabada) del delito en cuestión.

El fracaso de la "teoría de la peligrosidad", así diagnosticado, se explica por su incompatibilidad con la caracterización funcional del concepto de tentativa de delito como categoría de la parte general ${ }^{37}$. Que la tentativa de un delito cualquiera no exhiba la propiedad de ser típicamente adecuada, sino solo la de encontrarse referida al tipo en cuestión ${ }^{38}$, significa que la fijación de los presupuestos de punibilidad de una tentativa se ve necesariamente complementada por la descripción abstracta en la que consiste el tipo del delito de cuya tentativa se trata ${ }^{39}$. De ahí que un comportamiento que no llega a realizar (antijurídicamente) el tipo en cuestión pueda, no obstante, resultar imputable como la tentativa del delito así tipificado. La dependencia conceptual que exhibe la tentativa respecto del título de punibilidad autosuficiente en el que consiste el respectivo tipo-de-delito se manifiesta en la "formalidad materialmente 'ciega", que según Fincke es propia de las categorías de la parte general a través de las cuales puede verse ampliado o restringido el ámbito de punibilidad fijado a través de la correspondiente decisión autónoma de criminalización plasmada en la parte especial ${ }^{40}$. De esto se sigue que la estructura de imputación de la tentativa es conceptualmente compatible con toda forma de comportamiento típicamente relevante ${ }^{41}$.

La objeción referida a la imposibilidad de una generalización del criterio respectivo también afecta, mutatis mutandis, a la propuesta de determinar el inicio de la tentativa en atención a la variable de la generación de una conexión con la "esfera de la víctima", complementada por una exigencia de "proximidad temporal" 42 . Como debería ser obvio, la inadecuación de este planteamiento queda determinada por el hecho de que el criterio así

36 BERZ (1984) p. 513.

37 Véase Fincke (1975) pp. 28 s., 35 ss.; también Tiedemann (1992) pp. 10 ss.

38 Beling (1930) pp. 17 s.; en detalle, MañAlich (2017a) pp. 467 ss.

39 Véase KüHl (1980) pp. 506 ss. Claramente al respecto, Fiedler (1967) pp. 92 s.

40 FINCKE (1975) p. 27. De ahí que resulte categorialmente errada la observación de VogLER (1985) § 22, n.m. 58 ss., en cuanto a que "el problema de la demarcación de la preparación y la tentativa [sería] una pregunta específica de cada tipo”. En contra, Roxin (2003) § 29, n.m. 106 ss., quien observa que tal estrategia lleva a redefinir la pregunta como una "de la parte especial"; coincidentemente, ALCÁCER (2001) pp. 65 s. Para un intento de refutación de esta objeción, véase a su vez Vogler (1993) pp. 289 ss., quien no logra diferenciar suficientemente la correcta tematización de la referencia al respectivo tipo que es definitoria del concepto de tentativa, por un lado, de la problemática afirmación de que un comportamiento constitutivo de tentativa tendría que resultar "específico-del-tipo", por otro.

41 FinCKe (1975) p. 37. Al respecto, VogLer (1993) p. 290. Tal como lo mostrara Fincke, ello también vale en referencia a los así llamados "delitos de emprendimiento", tanto en su forma "propia" como en su forma "impropia”; véase FINCKE (1975) pp. 52 ss., quien acertadamente observaba que la extendida tesis según la cual la tentativa de un delito de emprendimiento no sería constructivamente concebible descansa en un desconocimiento de la diferencia entre el carácter formal del concepto de tentativa qua categoría de la parte general, por un lado, y el carácter material de la noción de intentar que se identifica con un componente explícito o implícito de la estructura típica del respectivo delito de emprendimiento, por otro.

42 Así y paradigmáticamente, Roxin (2003) § 29, n.m. 139 ss. 
propuesto resulta ab initio inaplicable tratándose de la tentativa de cualquier delito cuya estructura típica sea incompatible con la tematización de la posición de una víctima ${ }^{43}$. Esto no solo concierne a delitos consistentes en el quebrantamiento de normas que protegen bienes jurídicos colectivos, sino también a aquellos consistentes en el quebrantamiento de normas que dispensan protección general a un bien jurídico individual frente al peligro abstracto, esto es, que contribuyen a asegurar la disponibilidad despreocupada sobre un bien individual por parte de cualesquiera personas que funjan como sus titulares ${ }^{44}$, lo cual incluye a personas no involucradas en la situación potencialmente delictiva. En uno y otro ámbito, una apelación a la esfera de la víctima para especificar el punto a partir del cual la tentativa se encontraría iniciada es impertinente sin más, lo cual basta para descartar su aceptabilidad dogmática.

Por supuesto, lo anterior no quiere decir que la referencia a la posición de la víctima carezca de toda relevancia para la determinación del inicio de la tentativa de un delito cuyo fundamento de ilicitud se deje identificar con el menoscabo singularizado de un bien jurídico individual ${ }^{45}$. Pero esa eventual relevancia solo podrá ser mediata, y más precisamente: derivativa, en la medida en que el criterio general para el reconocimiento de un inicio de la tentativa de cualquier delito confiera significación a esa referencia.

\subsection{El CRITERIO DE LA ACCIÓN INTERMEDIA}

Como criterio para el inicio de la tentativa de un delito cualquiera solo puede venir en consideración una fórmula que resulte propiamente insensible a la especificidad de la estructura típica del delito de cuya posible tentativa se trata. Eso es, en principio, lo que ofrece la así llamada "teoría de la acción intermedia", que suele ser entendida como una especificación de la fórmula de Frank ${ }^{46}$. De acuerdo con ella, el potencial autor da inicio a la tentativa del delito respectivo si su comportamiento, según su representación de las circunstancias, "ha llegado ya tan lejos que la acción siguiente configuraría ya la realización (parcial) del tipo" ${ }^{47}$. Esta formulación necesita ser corregida en a lo menos tres aspectos para que el criterio goce de plausibilidad inicial. En primer lugar, y por las razones ya ofrecidas, hay que abandonar la tematización de una "realización parcial" del tipo. Adicionalmente, es necesario complementar la referencia a la potencial realización del tipo, en el sentido de que ha de tratarse de la potencial realización antijurídica del tipo en cuestión. Pues si el agente se representara circunstancias que, de concurrir objetivamente, darían lugar a una exclusión de la antijuridicidad del comportamiento proyectado, nos encontraríamos ante un error (“de tipo permisivo") excluyente del dolo, y así incompatible con una imputación a título de tentativa ${ }^{48}$. Finalmente, el nivel de generalidad que ha de exhibir el criterio exige que su formulación resulte inmediatamente pertinente con independencia del carácter comisivo u

\footnotetext{
43 Berz (1984) pp. 516 s.

44 Para la correspondiente distinción entre la protección general y la protección especial de un bien jurídico individual frente al peligro abstracto, véase KINDHÄUSER (1989) pp. 294 ss.

45 Véase ya Berz (1984) p. 517.

46 Así ya Gössel (1971) p. 226; también Rudolphi (1973) pp. 22 ss. Al respecto, véase Vogler (1993) pp. 285 ss.

47 BERZ (1984) p. 514.

$48 \mathrm{Al}$ respecto, Mañalich (2017a) pp. $466 \mathrm{~s}$.
} 
omisivo del delito de cuya tentativa se trata, y más abstractamente: con independencia de si el respectivo tipo-de-delito habría de verse realizado a través de un comportamiento consistente en la no-omisión o la no-ejecución de una acción de cierta clase ${ }^{49}$.

De ahí que pueda sugerirse la siguiente formulación provisional del criterio de la acción intermedia: hay inicio de la tentativa de un delito cualquiera, si y solo si para el potencial autor no es necesario ejecutar u omitir acción alguna para quedar en posición de ejecutar u omitir una acción que él tendría que omitir o ejecutar para dar seguimiento a una norma cuyas condiciones de aplicación resultarían satisfechas si su representación de las circunstancias resultara ser acertada, estando él resuelto a ejecutar u omitir la acción que, sobre la base de esa representación, él debería omitir o ejecutar. El carácter provisional de esta formulación se explica por el hecho de que todavía es necesario contrastar dos versiones posibles - una laxa y otra estricta- del criterio así presentado. Pero antes de entrar en ello es conveniente ofrecer un par de observaciones aclaratorias.

Como primer punto, hay que advertir que aquello que ocupa el lugar (hipotético) de la respectiva acción intermedia -a saber: la acción cuya ejecución u omisión sería necesaria para que el agente quede en posición de ejecutar u omitir la acción que tendría que omitir o ejecutar- no es otra cosa que una acción auxiliar en relación con la acción -en tal medida: principal- que el agente tendría que omitir o ejecutar para así dar seguimiento a la norma. $1^{50}$. Esta precisión hace posible observar, como segundo punto, que el criterio atribuye una función puramente negativa a la tematización de la correspondiente acción preparatoria en cuanto acción intermedia: el reconocimiento de un inicio de la tentativa depende de que, bajo su representación de las circunstancias, para el agente no sea necesario ejecutar u omitir alguna acción para así quedar en posición de ejecutar u omitir la respectiva acción principal ${ }^{51}$.

Esto último es de importancia por dos razones. La primera consiste en que la satisfacción del criterio no depende en lo absoluto de que en algún punto de tiempo haya sido necesaria la ejecución u omisión "preparatoria" de semejante acción intermedia. Esto basta para mostrar que el criterio no resulta comprometido con el problemático modelo del iter criminis, bajo el cual siempre tendría sentido postular un tránsito desde una "fase preparatoria" hacia una "fase ejecutiva" 52 . La segunda razón por la cual es importante el hallazgo de la función negativa del recurso a la respectiva acción intermedia radica en que por esa vía se vuelve inteligible que el criterio de la acción intermedia suela ser -correctamente- presentado en la forma de una exigencia (positiva) de inmediatez ${ }^{53}$. Pues que según su propia representación de las circunstancias para el agente no sea necesario ejecutar u omitir acción alguna para quedar en posición de ejecutar u omitir la acción que él tendría que omitir o

\footnotetext{
49 Esta puntualización tiene importancia en atención a las particularidades de la estructura típica de todo delito consistente en el quebrantamiento de una norma que no prohíbe o requiere acciones de cierta clase, sino actividades o estados de cierta clase, y que en tal medida se comporta como una norma "silogísticamente opaca"; véase Mañalich (2014) pp. 28 ss.

50 Véase Mañalich (2014) pp. 71 ss.

51 Fundamental al respecto, Vogel (1993) pp. 229 s.

$52 \mathrm{Al}$ respecto, Mañalich (2019b) II.1.

53 BERZ (1984) p. 514.
} 
ejecutar en pos del seguimiento de la norma, en principio tendría que significar que, bajo esa misma representación, él ya se encuentra en posición de ejecutar u omitir la respectiva acción principal.

Que lo anterior solo valga en principio, se sigue de que, según ya se anticipara, es posible contrastar dos versiones del criterio en cuestión: a saber: una laxa y una estricta, que en la terminología favorecida por Kratzsch respectivamente se corresponden con la "teoría material" y la "teoría formal" de la acción intermedia ${ }^{54}$. Para ilustrar en qué consiste cada una de ellas, cabe dar la palabra a Berz: "Si uno quisiera aquí responder la pregunta acerca de [la necesidad de] cualesquiera actos intermedios de manera puramente formal, con la vista puesta en acciones corporales que seguirían siendo necesarias, entonces uno obtendría un criterio de demarcación sumamente exacto, pero con el desmembramiento del curso de acción al mismo tiempo restringiría en demasía el estadio de la tentativa y se expondría al reproche del 'derecho penal de la lupa temporal'" 55.

Esta última noción metafórica, acuñada por Geilen ${ }^{56}$, es especialmente adecuada para detectar qué está en juego en el contraste de una formulación laxa y una formulación estricta del criterio de la acción intermedia. Considérese el caso siguiente:

En el instante preciso en que A toma la pistola previamente liberada de su seguro, con la cual él quiere disparar contra $\mathrm{X}$, aquel es detenido por un policía ${ }^{57}$.

Berz observa que "aquí uno no podrá negar el inicio de la tentativa por el hecho de que entre el tomar la pistola y la acción típica del § 212, el 'matar' (= disparar), eran necesarios ulteriores 'actos intermedios' (preparar el disparo y apuntar)" ${ }^{58}$. Más plausible sería asumir que A ya habrá dado inicio a la tentativa de homicidio, con independencia de que para él todavía fuese necesario ejecutar una o más "acciones corporales" ulteriores para así poder efectuar un disparo dirigido contra X. Lo decisivo sería, más bien, juzgar lo acontecido bajo la pregunta de si, en los términos de la fórmula de Frank, desde una "concepción natural" el comportamiento ya desplegado por A habría de ser evaluado como integrando una unidad en la que también habría de resultar comprendido el eventual disparo del arma ${ }^{59}$. Ello iría de la mano de una discriminación entre aquellas acciones intermedias que por su carácter de "esenciales" obstarían, en cuanto todavía necesitadas de ejecución, al reconocimiento del inicio de la eventual tentativa, y aquellas acciones intermedias "no esenciales", la necesidad de cuya ejecución no impediría tener por iniciada la tentativa en cuestión ${ }^{60}$.

\footnotetext{
54 Kratzsch (1983) pp. 422 s.

55 Berz (1984) p. 514.

56 GeIlen (1977) p. 164. Al respecto, KüHL (1980) p. 652; AlcÁcer (2001) p. 71.

57 BERZ (1984) p. 514.

58 BERZ (1984) p. 514.

59 Berz (1984) p. 514. Críticamente acerca de la pertinencia jurídico-penal de semejante apelación a la "concepción natural”, contenida en la fórmula de Frank, KüHL (1979) p. 718.

60 Así Kühl (1980) p. 652; Berz (1984) p. 514; coincidentemente, Alcácer (2001) pp. 71 s. Críticamente, Murmann (1999) pp. $24 \mathrm{~s}$.
} 
Que el recurso a la noción de una "unidad natural de acción" deba entenderse como complementario del criterio de la acción intermedia ${ }^{61}$, y no en cambio como un criterio alternativo (aunque próximo) a este ${ }^{62}$, no necesita ser zanjado aquí. Más importante es constatar la laxitud con la que, por esa vía, llega a ser manejado el criterio de la acción intermedia, tal como lo documenta una célebre decisión del $\mathrm{BGH}^{63}$, referida a un caso cuyas circunstancias Kratzsch sintetizara como sigue:

K y L se aproximaron a la vivienda de T, para robar en ella. Ante la puerta de la casa se pusieron sus máscaras de medias. Entonces K, sosteniendo una pistola en la mano, tocó a la puerta. Los hechores asumían que ante su llamado aparecería T o alguna otra persona. La persona que abriera debería ser enseguida amenazada con la pistola y amarrada, para así robarle. Tras el golpe a la puerta nadie apareció. Tampoco fueron exitosos los llamados hechos a través de varias ventanas ${ }^{64}$.

Según el BGH, la exigencia de que el comportamiento del autor hubiera de desembocar "sin actos intermedios" en la realización del tipo no debería ser interpretada demasiado estrictamente, pudiendo concluirse así que a $\mathrm{K}$ y L habría sido imputable una tentativa (inacabada) de robo ${ }^{65}$. Esto muestra cuán dúctil puede llegar a ser el criterio de la acción intermedia cuando su presentación no va acompañada de una especificación de sus condiciones de aplicación, y cuán fundado era el llamado de atención de Von Hippel en cuanto al riesgo de relajación al que aquel se ve enfrentado, riesgo que se ve intensificado por la tendencia a cualificar el test provisto por el criterio en cuestión a través de la distinción entre acciones intermedias "esenciales" y "no esenciales". Ciertamente, la posibilidad de semejante pérdida de contornos no es un defecto endémico de la propuesta demarcatoria así articulada. Una indeterminación todavía más aguda afecta, por ejemplo, a la fórmula de la "prueba de fuego de la situación crítica", que a veces es redefinida a través del recurso al eslogan del "ahora empieza" (jetzt geht es los) ${ }^{66}$. Frente a esta última propuesta, el criterio de la acción intermedia exhibe al menos la ventaja de vincular expresamente el reconocimiento del inicio de la tentativa del delito respectivo con la realización (antijurídica) del tipo correspondiente. Esta constatación ofrece un punto de partida para intentar alcanzar una formulación más precisa del criterio de la acción intermedia, que tendría que tender a acercarse a su versión estricta.

\footnotetext{
${ }^{61}$ Así Berz (1984) pp. 514 s., denunciando que la praxis judicial alemana ha tendido a argumentar de manera circular, por la vía de hacer uso, indistintamente, de alguna de esas dos fórmulas para intentar precisar las condiciones de aplicación de la otra.

62 Así Kratzsch (1983) pp. 422 s.

63 BGH 1 StR 264/75, sentencia de 16 de septiembre de 1975.

64 Kratzsch (1983) p. 422

65 En referencia al mismo caso, y defendiendo la corrección de la solución alcanzada por el BGH, KüHL (1980) p. 654 .

66 Véase Berz (1984) p. 516. Críticamente acerca de la confusión tendencial de tal eslogan con la mera insistencia en la exigencia de una correspondiente resolución-al-hecho, SAFFERLING (2006) pp. 688 s., 700 s.; véase ya Heintschel-Heinegg (1997) p. 38, nota 39.
} 


\section{ACCIÓN INTERMEDIA Y OPORTUNIDAD PARA-LA-ACCIÓN}

\subsection{El MODELO DE LA OPORTUNIDAD-PARA-LA-ACCIÓN}

Una herramienta conceptual promisoria para la exploración recién sugerida puede encontrarse en lo que aquí será denominado el "modelo de la oportunidad-para-la-acción", que se deja extraer de la teoría de la acción elaborada por Von Wright ${ }^{67}$. Un aspecto central de esta consiste en la clarificación de la manera en que la "lógica de la acción" se encuentra anclada en una correspondiente "lógica del cambio"68. La premisa decisiva para ello se encuentra en la consideración de que la marca de éxito de una acción está necesariamente constituida por lo que Von Wright llama una "transformación". Por tal cabe entender la sucesión de un "estado inicial" por un "estado terminal" "69, siendo ello compatible con que entre uno y otro estado se dé una relación de identidad. Así, si "e" simboliza un estado cualquiera, "ᄀ" funge como el operador de la negación y "T" simboliza la sucesión entre dos estados que es constitutiva de la respectiva transformación, entonces una acción puede exhibir una y nada más que una de las siguientes cuatro estructuras ${ }^{70}$, a saber:

$\phi(\neg e T e)$, consistente en la producción de un estado;

$\phi(\mathrm{e} T\urcorner \mathrm{T})$, consistente en la destrucción de un estado;

$\phi(\mathrm{eTe})$, consistente en la preservación de un estado;

$\phi(\neg e T\urcorner e)$, consistente en la prevención de un estado.

Si por vía de simplificación identificamos el resultado de la acción respectiva con la correspondiente transformación como tal ${ }^{71}$, entonces podemos decir que la marca de éxito de una acción habrá de consistir en el acaecimiento -si la acción es de tipo productivo o destructivo- o el no-acaecimiento -si lo es de tipo preservativo o preventivo- de un cambio relativo a un cierto estado ${ }^{72}$. Así, que una acción particular ejemplifique el correspondiente tipo de acción dependerá de que ella resulte en el acaecimiento o el no-acaecimiento del cambio en cuestión. Y la relación expresada por esta fórmula de "resultar-en" puede ser definida como una relación de condicionamiento causal o constitutivo del acaecimiento o noacaecimiento del cambio correspondiente, según si este consista en un evento perteneciente al nivel de la realidad natural o de la realidad institucional, respectivamente ${ }^{73}$.

\footnotetext{
67 Para lo que sigue, en detalle, Mañalich (2018) pp. 96 ss.

68 Von Wright (1963) pp. 17 ss., 42 ss. Véase Sosa (1965) passim; Hilpinen (2016) pp. 51 ss. Latamente sobre ello, GonZÁlez LaGier (1995) pp. 189 ss.

69 O bien: de un estado por un proceso, de un proceso por un estado, o de un proceso por otro proceso; véase Von Wright (1963) pp. 27 s.

70 Acerca de los correspondientes cuatro tipos básicos (de tipos) de acción, Von Wright (1963) pp. 43 ss.; también KINDHÄUSER (1989) pp. $50 \mathrm{~s}$.

71 Véase Von Wright (1963) p. 42.

72 Von Wright (1963) pp. 42 ss.

73 Para la correspondiente distinción entre descripciones-de-acción causalmente complejas y constitutivamente complejas, véase Searle (2010) pp. 36 ss.; al respecto, también Olave (2018) pp. 195 ss.
} 
Con ello quedamos en condiciones de definir el concepto de oportunidad-para-laacción, en referencia a un tipo de acción cualquiera. Generalizando la definición explícitamente ofrecida por Von Wright ${ }^{74}$, podemos decir que la respectiva oportunidad-parala-acción se identifica con una situación en la cual para el agente es posible condicionar el acaecimiento o no-acaecimiento del cambio respectivo, satisfaciendo la descripción que especifica el correspondiente tipo de acción. Ello depende, a su vez, de la satisfacción de dos condiciones más básicas: en primer lugar, que sea lógicamente posible el acaecimiento o el no-acaecimiento del cambio en cuestión, según corresponda; y en segundo lugar, que a través de la ejecución o la omisión de la acción respectiva el agente haya de hacer una diferencia en cuanto a si acaece o no acaece el cambio en cuestión ${ }^{75}$. Por vía de ejemplo: cuenta con una oportunidad-para-la-acción relevante bajo la prohibición del homicidio quien se encuentra en posición de producir la muerte de otro ser humano (nacido). Si la pregunta no se plantea respecto de un tipo de acción puramente resultativa, sino respecto de un tipo de acción modalmente especificado, la configuración de la correspondiente oportunidadpara-la-acción dependerá de que el agente se encuentre en posición de condicionar el acaecimiento o no-acaecimiento del cambio en cuestión a través del correspondiente "modo de operación"76. Por vía de ejemplo: cuenta con una oportunidad-para-la-acción relevante bajo la prohibición de la estafa quien se encuentra en posición de condicionar, mediante engaño, una disposición patrimonial perjudicial para otra persona.

\subsection{El CRITERIO DE LA “INMEDIATEZ-DE-ACCIÓN"}

El modelo de la oportunidad-para-la-acción hace posible reconstruir satisfactoriamente el criterio de reconocimiento de un inicio de la tentativa asociado al test de la acción intermedia, y más precisamente: en la forma de un criterio de "inmediatez-de-acción"77. Siguiendo a Vogel, tal reformulación puede obtenerse recurriendo a la distinción entre los conceptos de acción básica y acción mediada, para así dar precisión a la distinción, ya introducida, entre los conceptos de acción principal y acción auxiliar ${ }^{78}$.

Es usual que la primera de las dos distinciones recién enunciadas sea presentada de la siguiente manera: una acción cuenta como mediada si su ejecución u omisión tiene lugar a través de la ejecución u omisión de alguna otra acción ${ }^{79}$; una acción cuenta como básica (o "primitiva"), en cambio, si su ejecución u omisión no tiene lugar a través de la ejecución de alguna otra acción ${ }^{80}$. En estos términos, la caracterización de una acción como básica

\footnotetext{
74 Von Wright (1963) p. 37.

75 Esta segunda condición (de carácter contrafactual) es enunciada por Von Wright como consistente en que el cambio en cuestión no haya de tener lugar "por sí mismo"; véase VON WRIGHT (1963) pp. 44 s., considerando el problema planteado por casos de "causalidad alternativa" y acertadamente llegando a la conclusión de que el comportamiento de los dos o más agentes involucrados es individualmente causal para el acaecimiento del evento constitutivo del resultado.

76 Para esta noción, véase HACKer (2007) p. 126.

77 Fundamental, KüHL (1980) pp. 650 ss., 811 ss.; al respecto, supra, 2.3.

78 Vogel (1993) pp. 74, 239 ss.

79 La terminología procede de DANTO (1973) pp. $28 \mathrm{~s}$.

80 Así precisamente STOUTLAND (1968) pp. 468 ss., 471 ss.; KindHÄUSER (1980) pp. 488 ss. Véase también Duff (1996) pp. 246 ss. Al respecto, MaÑAlich (2012) pp. 679 ss.
} 
o como mediada es relativa a alguna descripción: una acción a través de cuya ejecución u omisión se ve ejecutada u omitida alguna otra acción cuenta como básica respecto de esta, la cual a su vez cuenta como mediada respecto de aquella ${ }^{81}$. Así por ejemplo, si A jala el gatillo de un arma de fuego, y esto resulta en que el arma sea disparada, entonces podemos decir que, por la vía de jalar el gatillo, A ha disparado el arma; y si de esto último resulta que B sea letalmente impactado por la bala expedida, entonces podemos asimismo decir que, por la vía de disparar el arma -y por transitividad: por la vía de jalar el gatillo del arma-, A ha matado a B.

Lo anterior no quiere decir que quien ejecuta alguna acción (mediada) por la vía de ejecutar una acción más básica ejecute varias acciones, en el sentido de dos o más acciones numéricamente diferentes. En referencia al ejemplo precedente no parece plausible afirmar, en efecto, que A habría ejecutado no una, sino tres acciones, a saber: la acción consistente en jalar el gatillo, la acción consistente en disparar el arma, y la acción consistente en matar a $\mathrm{B}^{82}$. Antes bien, es ontológicamente más ahorrativo asumir que aquí no cabe diferenciar tres acciones, sino solo tres descripciones de una misma acción ejecutada por A, que en tal medida ejemplifica los tipos de acción especificados a través de esas tres descripciones ${ }^{83}$. Que múltiples tipos de acción se vean ejemplificados por una misma acción es algo que depende de la relación de causalidad o constitución que vincule a los eventos identificados como los respectivos resultados de la acción bajo sus respectivas descripciones.

En jerga filosófica, semejante mecanismo de redescripción de acciones se conoce como efecto acordeón, en atención a la manera en que lo que un agente hace o no hace en una determinada situación puede verse expandido o contraído en función de las descripciones más o menos complejas que resultan verdaderas de la acción ejecutada u omitida por él ${ }^{84}$. En el ejemplo ya considerado, la acción de jalar el gatillo del arma, ejecutada por A, puede ser redescrita como la acción de disparar el arma, en razón de la conexión causal existente entre el jale del gatillo y el evento consistente en que una bala salga proyectada desde el arma; y la acción así ya descrita puede ser a su vez redescrita como la acción de matar a $\mathrm{B}$, en razón de la conexión causal existente entre el disparo del arma y el acaecimiento de la muerte de B. Lo mismo vale, mutatis mutandis, cuando la conexión que hace posible la redescripción de la acción respectiva no tiene carácter causal, sino constitutivo: quien toma y se lleva una cosa que se encuentra en un cierto lugar puede estar ejecutando, por esa vía, una acción consistente en sustraer esa cosa, en la medida en que esta se haya encontrado en poder -en el sentido de: en "custodia" - de otra persona que a su vez no haya estado de acuerdo con que ella fuese tomada y llevada por la primera ${ }^{85}$.

\footnotetext{
81 Acerca de la relatividad del concepto de acción básica, véase KindHÄUSER (1980) pp. 489 s.

82 Esta es la conclusión a la cual lleva la adopción de una tesis intensionalista (o "de grano fino") para la individuación de acciones; así Goldman (1970) pp. 1 ss., 10 ss.; KindHÄUser (2011) pp. 46 s.

83 Esto es lo que se sigue de la adopción de una tesis extensionalista (o "de grano grueso") para la individuación de acciones; así Anscombe (1963) pp. 37 ss., 45 ss.; Davidson (2001) pp. 43 ss., 128 ss., 163 ss.

84 Fundamental Feinberg (1970) pp. 132 ss.; también Davidson (2001) pp. 53 ss. Para la comparación de una y otra concepción, Bratman (2006) passim. Al respecto, véase KindHÄUSER (1989) pp. 50 ss.; KindHÄUSER (2011) pp. 44 ss.

${ }^{85}$ Véase Olave (2018) pp. $198 \mathrm{~s}$.
} 
Como sugiriera Vogel, el inicio de la tentativa de un delito consistente en el quebrantamiento de una norma de prohibición o de requerimiento de acciones de cierto tipo necesita quedar referido a la ejecución u omisión de una acción básica que habría de contar como una acción principal bajo la norma correspondiente ${ }^{86}$. Según lo ya explicado, esto quiere decir que el agente ha de encontrarse en posición de ejecutar u omitir una acción que, de ser acertada su representación de las circunstancias, habría de llegar a ejemplificar, vía redescripción, el tipo de acción sometido a prohibición o requerimiento. De ahí que, por ejemplo, no pueda entenderse iniciada la tentativa de un delito de abuso sexual de menor impúber en un instante en que el potencial autor se encuentre todavía desplazándose, ya acompañado del menor, hacia el lugar en el que habría de ser desplegada la acción sexual ${ }^{87}$. Y que bajo la representación de las circunstancias atribuible al agente este se encuentre en posición de ejecutar u omitir la correspondiente acción básica, no es algo que a su vez dependa de las creencias o las convicciones del agente. Esto hace reconocible que, como tal, el criterio de la inmediatez-de-acción tiene el carácter de un estándar objetivo, cuya aplicación ha de entenderse referida a las circunstancias fácticas que el agente tiene por existentes ${ }^{88}$.

Según Vogel, el instante "más temprano" en que podría verse iniciada la tentativa correspondiente admitiría ser identificado con la conclusión de la ejecución de la o las acciones preparatorias eventualmente necesarias, bajo la representación de las circunstancias atribuible al agente, para la configuración de la respectiva oportunidad-para-la-acción ${ }^{89}$. Pues ese es el instante en que el agente quedaría en posición de realizar su intención constitutiva de la respectiva resolución-al-hecho, por la vía de ejecutar u omitir una acción cuya omisión o ejecución es prácticamente necesaria para dar seguimiento a la norma. Como contrapartida, el instante "más tardío" para el reconocimiento de un inicio de la tentativa habría de identificarse con el momento en que el agente (ya) da inicio a la ejecución de la acción que él tendría que omitir bajo la respectiva norma de prohibición, o bien no da inicio a la ejecución de la acción que tendría (ya) que ejecutar bajo la respectiva norma de requerimiento, según corresponda ${ }^{90}$.

\footnotetext{
${ }^{86}$ Vogel (1993) pp. 230 ss. Véase, sin embargo, KindHÄUser (2018) pp. 137 ss., según quien el comportamiento desplegado por el autor de una tentativa inacabada no se dejaría identificar con el comportamiento cuya evitación sería prácticamente necesaria para dar seguimiento a la norma, lo cual llevaría a la conclusión de que ese comportamiento "no contraviene, bajo su consideración aislada, la prohibición de la acción principal" (p. 138). Al respecto, y críticamente, Mañalich (2019b) V.

87 Así empero KüHl (1980) pp. 811 s., a propósito de la complementación del criterio de la inmediatez-deacción a través de un criterio de "inmediatez temporal".

88 Así ya KüHL (1980) pp. 811, 813. Fundamental al respecto, Fiedler (1967) pp. 92 s., recurriendo a la formulación favorecida por VON GEMMINGEN (1932) p. 137, según quien la determinación del inicio de la tentativa tendría la forma de una "demarcación objetiva de una subjetividad objetivada".

89 Vogel (1993) pp. 230 s.; en esta dirección ya Rudolphi (1973) p. 22, aun cuando sin exigir el término de la ejecución de la acción inmediatamente previa a la acción a través de cuya ejecución u omisión habría de ser realizado el tipo-de-delito.

90 Véase Vogel (1993) pp. 231 ss., haciendo explícito que, tratándose de la tentativa de un delito de omisión impropia, su inicio depende de que, bajo la representación de las circunstancias atribuible al garante, se haya configurado un peligro concreto para el bien jurídico cuya salvaguarda es requerida y no sea segura la posibilidad de un posterior impedimento del resultado.
} 
La posibilidad de diferenciar el instante más temprano y el más tardío en que puede reconocerse iniciada la tentativa de un delito tiene importancia para la contrastación de las fórmulas legislativas susceptibles de ser reconstruidas como modulaciones alternativas del criterio genérico así perfilado, como lo es, verbigracia, la fórmula del "principio de ejecución" contenida en el inc. $3^{\circ}$ del art. $7^{\circ}$ del Código Penal ${ }^{91}$. Aquí interesa, más bien, hacer explícitas las ventajas asociadas a la reformulación del criterio de la acción intermedia en el sentido del criterio de la inmediatez-de-acción.

Según ya se sugiriera, el criterio de la acción intermedia opera, literalmente, en la forma de un test negativo: no hay inicio de la tentativa en la medida en que el agente todavía necesite ejecutar alguna acción -en tal medida: preparatoria- que lo deje en posición de ejecutar u omitir la acción cuya ejecución u omisión exhibe relevancia delictiva. Una primera ventaja asociada a su reformulación como un criterio de inmediatez-de-acción radica en el carácter positivo del test así obtenido: la tentativa de un delito cualquiera se encuentra iniciada en el instante en que el agente, estando resuelto-al-hecho y según su representación de las circunstancias, cuenta ya con la oportunidad para ejecutar u omitir una acción (básica) que él tendría que omitir o ejecutar para así dar seguimiento a la norma respectiva.

El punto es importante, desde ya, en cuanto hace posible abandonar la hipótesis, favorecida por el modelo del iter criminis, de que toda tentativa se vería precedida por la ejecución de una o más acciones preparatorias. A ello se añade el hecho de que, por esa misma vía, resulta fácil alcanzar la solución intuitivamente adecuada para aquellos casos en los cuales la (eventual) última acción preparatoria desplegada por el agente pudo quedar íntegramente ejecutada "ya un largo tiempo antes" de que hubiera de ser ejecutada u omitida la acción cuya ejecución u omisión habría de resultar típicamente relevante. Aquí no se trata de que un pretendido criterio (complementario) de "inmediatez temporal" aparezca corrigiendo la aplicación del criterio de la inmediatez-de-acción ${ }^{92}$. Antes bien, se trata de que la conclusión de la (eventual) preparación de la perpetración de un delito carece de relevancia criteriológica autónoma para la determinación de cuándo se ve actualizada la respectiva intención previa, atribuible al agente, en la forma de la correspondiente resolución-al-hecho ${ }^{93}$.

Lo anterior se encuentra internamente conectado con una segunda ventaja asociada a la fórmula de la inmediatez-de-acción. Esta consiste en la superación de la hipótesis de que el reconocimiento del inicio de una tentativa necesariamente dependería de la constatación de una "transición conductual" atribuible al destinatario de la norma, esto es, de la constatación de que este empezaría a hacer algo que hasta ese momento no estaba haciendo, o bien de que empezaría a abstenerse de hacer algo de lo que hasta ese momento no se estaba absteniendo. Considérese el caso siguiente:

El sicario $S$ se ha instalado en la azotea de un edificio de mediana altura, desde donde logra apuntar su rifle de largo alcance hacia el lugar donde tendría que aparecer $P$, la persona que se le ha encomendado matar. Transcurridos unos pocos minutos, y

\footnotetext{
${ }^{1}$ Problema al cual será destinado un trabajo posterior.

92 Así empero, KüHL (1980) p. 812.

93 Véase Mañalich (2019b) IV.1.
} 
mientras $S$ mantiene el rifle apuntado hacia el lugar, aparece $\mathrm{P}$; $\mathrm{S}$ no alcanza a tirar del gatillo antes de que P súbitamente desaparezca del sitio.

De acuerdo con el criterio de la inmediatez-de-acción, $S$ da inicio a una tentativa de homicidio en el instante en que, según su representación de las circunstancias, aparece la persona que $S$ identifica como aquella persona en relación con quien $S$ ya se ha formado, previamente, la intención de disparar su rifle, intención que se ve actualizada como resolución-al-hecho en ese mismo instante ${ }^{94}$. Pues la situación que $S$ se representa como dada en ese instante es una que, configurándose objetivamente, proveería a aquel de la oportunidad para ejecutar una acción que él se encuentra resuelto a ejecutar y que él, empero, tendría que omitir para así dar seguimiento a la prohibición del homicidio, sin que en ese preciso instante $S$ llegue a ejecutar acción alguna ${ }^{95}$. Puesto que $S$ ya se encuentra apuntando el rifle hacia el lugar en el que debería aparecer $P$, para que se configure la oportunidad para que $S$ efectúe el disparo eventualmente letal basta con que, bajo la representación de $S$, aparezca la persona que $S$ identifica como P. Esta es ciertamente una transformación de la situación del mundo que $S$ se representa como dada, que no se corresponde con una transición conductual de su parte.

\subsection{El FACTOR DE LA SUERTE CIRCUNSTANCIAL}

En contra de una formulación estricta del criterio de la inmediatez-de-acción ha sido esgrimida la objeción de que por tal vía el reconocimiento del inicio de la tentativa quedaría sometido, tal como ya se observara, a una "lupa temporal" 96 . La objeción apunta a que, según cómo se encuentre configurada la situación del agente, parecería contraindicado que la necesidad de que todavía sean ejecutados "actos parciales no esenciales" para que aquel quede en posición de ejecutar u omitir una acción que, bajo su representación de las circunstancias, él tendría que omitir o ejecutar para así dar seguimiento a la norma, obste a la imputación de la tentativa del delito correspondiente.

El problema se muestra de modo especialmente ilustrativo en un caso del que conociera el $\mathrm{BGH}^{97}$, y que para lo que aquí interesa podemos resumir como sigue:

Un hombre $\left(\mathrm{H}_{1}\right)$, que acaba de ser liberado de prisión, pretendía hacer ingreso a la vivienda que él compartiera con su cónyuge $(\mathrm{M})$, donde desde hace unos meses se encontraba residiendo, junto con $\mathrm{M}$, otro hombre $\left(\mathrm{H}_{2}\right)$, otrora compañero de presidio de $\mathrm{H}_{1}$. A través de un proceso desarrollado en rebeldía, $\mathrm{H}_{1}$ había conseguido que $\mathrm{H}_{2}$ fuese obligado a hacer abandono de la vivienda, sin que ello hubiese ocurrido hasta entonces. Un día, y después de varios intentos de que $\mathrm{M}$ le abriera la puerta, $\mathrm{H}_{1}$ logró

\footnotetext{
${ }_{94}$ Que la persona que S identifica como P en efecto sea P, carece de toda relevancia para la imputación, en razón de la irrelevancia de un posible error in personae vel objecto para la constitución del dolo de homicidio.

95 Ello no se ve alterado por el hecho de que, como en efecto ocurre, P desaparezca del lugar antes de que $S$ llegue a tirar del gatillo, en la medida en que, al advertir la aparición del primero, $S$ haya asumido que contaba con la chance de efectuar el disparo.

96 Véase KÜHL (1980) p. 652; también Berz (1984) p. 514.

${ }^{97}$ BGH 1 StR 703/79, sentencia de 4 de diciembre de 1979.
} 
traspasar un panel provisoriamente fijado en la puerta de entrada de la casa. Ante ello, $\mathrm{H}_{2}$ tomó un hacha que se encontraba en el garaje, para procurar impedir el ingreso de $\mathrm{H}_{1}$ y, de ser necesario, golpearlo con ella. Al advertir $\mathrm{H}_{1}$ que $\mathrm{H}_{2}$ se aproximaba hacia él con el hacha, aquel se adelantó avanzando en dirección al segundo, logrando sujetar el hacha con sus dos manos y así impedir que $\mathrm{H}_{2}$ le propinase el golpe con ella, tras lo cual un conocido de $\mathrm{H}_{1}$ logró arrebatar el hacha de las manos de ambos.

El BGH resolvió no confirmar la sentencia condenatoria por tentativa de homicidio que había sido pronunciada en contra de $\mathrm{H}_{2}$, por no haberse comprobado que este hubiese logrado sostener el hacha de un modo que le hubiera hecho posible propinar un golpe con ella a $\mathrm{H}_{1}$, sin poder descartar que, ante el adelantamiento de $\mathrm{H}_{1}, \mathrm{H}_{2}$ hubiese tenido que retroceder un par de pasos para recién entonces quedar en posición de materializar un hachazo en su contra.

Según Kühl, la "fina diferenciación" sugerida por el BGH no resultaría convincente si se la interpreta como conducente a la "desintegración de un suceso con caracteres de homicidio en actos parciales", aun cuando ella sí sería plausible si se la toma como descansando en la hipótesis de que $\mathrm{H}_{2}$ solo habría pretendido efectuar un gesto amenazante con relevancia típica a título de coacción, mas sin haber estado todavía inmediatamente resuelto o dispuesto a ejecutar una acción potencialmente homicida ${ }^{98}$. Pero esto no hace justicia a la "fina diferenciación" en cuestión, a la vez que amenaza con redefinir subjetivistamente el criterio de la inmediatez-de-acción. La observación de Kühl parece sugerir que tendría sentido preguntar si $\mathrm{H}_{2}$ estaba ya resuelto a ejecutar una acción eventualmente letal para $\mathrm{H}_{1}$, o bien si $\mathrm{H}_{2}$ estaba inmediatamente dispuesto -según la fórmula plasmada en el $\S 22$ del StGB- a ejecutar tal acción, con prescindencia de si la situación en la que se encontraba $\mathrm{H}_{2}$, bajo su representación de las circunstancias, le confería ya una oportunidad para ejecutar tal acción.

De ahí que la distinción planteada por el BGH resultara enteramente pertinente. Si para $\mathrm{H}_{2}$ todavía resultaba necesario, según su representación de las circunstancias, retroceder unos pasos para quedar en posición de desplegar, sujetando el hacha con sus dos manos, el (articulado y coordinado) movimiento corporal necesario para dar con ella un golpe a $\mathrm{H}_{1}$, entonces $\mathrm{H}_{2}$ no llegó a estar, bajo su propia representación de las circunstancias, en posición de atacar letalmente a $\mathrm{H}_{1}$. Ello nada tiene que ver con una supuesta opción por "desintegrar" un suceso unitario en múltiples "actos corporales" 99 . Pues es claro que si $\mathrm{H}_{2}$ hubiese alcanzado a retroceder un par de pasos, quedando entonces en posición de propinar el hachazo, la materialización de este habría descansado en un extendido desplazamiento de los brazos de $\mathrm{H}_{2}$, acompañado de una exigente sujeción del hacha con sus dos manos, así como de un giro de su cadera y una multiplicidad de (difícilmente observables) contracciones musculares de su parte. Ello ciertamente no obstaría a la afirmación de que, en tal

\footnotetext{
98 KÜHL (1980) p. 652.

99 Véase Fiedler (1967) p. 90, quien en lo tocante al problema de la "división de acciones" (Gliederung von Handlungen), observaba que aquí no se trataría "de una consideración microscópica de conformaciones unitarias de procesos motores, sino exclusivamente de la consideración macroscópica de conformaciones unitarias al interior de cadenas de acción quizá vastamente extendidas".
} 
caso, el golpe con el hacha que $\mathrm{H}_{2}$ hubiese logrado propinar a $\mathrm{H}_{1}$ habría descansado en la ejecución de una acción básica por parte del primero, cuyo carácter de tal sería relativo a la complejidad que, comparativamente, habría exhibido la acción ejecutada por $\mathrm{H}_{2}$ si el golpe hubiese resultado en la muerte de $\mathrm{H}_{1}$.

La relatividad situacional de lo que cuenta como una acción básica, cuya ejecución u omisión pueda identificarse, en las circunstancias apropiadas, con la ejecución u omisión de una acción de mayor complejidad, habla fuertemente a favor de la tesis de la irreductibilidad de una acción básica cualquiera a algún simple movimiento corporal ${ }^{100}$. Qué movimientos corporales eventualmente tenga que desplegar o no desplegar un agente para ejecutar u omitir, en una determinada situación, una cierta acción, es algo que depende de factores que definen esa misma situación, así como de factores que definen la identidad y la posición del agente, entre los cuales ciertamente han de entenderse incluidas capacidades y otras propiedades disposicionales atribuibles a aquel. En la medida en que un agente nunca tendrá pleno control sobre los factores de esta última clase, la respuesta a la pregunta acerca de lo que alguien está en posición de hacer en una determinada situación quedará condicionada por un aspecto de suerte constitutiva. Y en la medida en que un agente tampoco tendrá pleno control sobre los factores de la primera clase, la respuesta también quedará condicionada por un aspecto de suerte circunstancial ${ }^{101}$.

En su mejor versión posible, la objeción asociada a la denuncia de un modelo de "derecho penal de la lupa temporal" parece ser reconducible a este último problema. A modo de ejemplo: que un agente tenga que ejecutar una acción susceptible de ser descrita como apuntar un arma de fuego hacia un lugar determinado, antes de poder efectuar un disparo eventualmente letal para otro ser un humano, depende, entre otras cosas, de cuál sea la distancia que separe al agente de su potencial víctima, de cuán ducho sea el primero en el uso de armas de fuego y así de cuánta precisión de maniobra necesite exhibir al efectuar el eventual disparo. Llevando el ejemplo al extremo: sería ciertamente curioso sostener que, en el marco de un duelo celebrado según el canon sugerido por el género del spaghetti western, cualquiera de los dos pistoleros involucrados que ya hubiera empuñado y desenfundado su revolver todavía tendría que apuntar el arma hacia su rival antes de poder disparar en su contra.

Que la suerte circunstancial juegue un papel para nada despreciable en la determinación de aquello que una persona, bajo su propia representación de las circunstancias, está en posición de hacer o no hacer, no nos debería preocupar. Pues si tal preocupación fuese consistentemente implementada, en términos tales que ningún agente pudiera verse libre de responsabilidad jurídico-penal por el hecho de haber quedado azarosamente privado de la posibilidad de desplegar un comportamiento potencialmente delictivo, entonces ten-

\footnotetext{
100 Véase ya KindHÄUSER (1980) p. 490.

101 Acerca de ambas variantes de la así llamada "suerte moral", en conjunción con aquellas del azar en cuanto a las condiciones antecedentes (o "suerte causal") y del azar en cuanto a las consecuencias (o "suerte consecuencial”), fundamental NaGel (1979) pp. 24 ss., 32 ss.; en perspectiva jurídico-penal, Malamud (2008) pp. 39 ss., 68 ss., así como BEADE (2017) pp. 38 ss. Al respecto, MAÑAlich (2017a) pp. 481 s., con referencias ulteriores. Para un iluminador análisis de la relación en que se encuentran las nociones de suerte moral y "suerte jurídica", ENOCH (2010) pp. 48 ss.
} 
dríamos que renunciar enteramente a la demarcación de lo que cuenta como una tentativa frente a lo que puede contar como ("mera") preparación.

En la literatura filosófica, el problema ha sido captado con exactitud por Michael Zimmerman. Este parte contrastando el caso en que una persona dispara un arma de fuego apuntando en contra de otra, resultando el disparo letal para esta, con un caso en que una persona también dispara un arma de fuego apuntando en contra de otra, pero sin que el disparo impacte a esta. El contraste mostraría la existencia de una diferencia en el alcance de la responsabilidad atribuible a uno y otro agente, al mismo tiempo que una identidad de grado entre una y otra ${ }^{102}$. Esto último sería lo decisivo, según Zimmerman, para sustentar la tesis de la irrelevancia moral de la suerte consecuencial. Es indudable, con todo, que jurídico-penalmente la sola diferencia en el alcance de la respectiva responsabilidad tiene -a lo menos- impacto penológico ${ }^{103}$, en la medida en que el respectivo sistema jurídico prevea regímenes punitivos diferenciados para la consumación y la tentativa en cuanto formas de punibilidad ${ }^{104}$. Pero ahora interesa notar que semejante diferencia entre el alcance y el grado de la responsabilidad también adquiere significación a propósito del aspecto de la suerte circunstancial, que forma parte de lo que Zimmerman tematiza como "suerte situacional"105.

Para ilustrar el problema, Zimmerman vuelve a contrastar dos casos, el primero de los cuales es idéntico al primero de los dos casos precedentemente examinados. La particularidad ahora relevante la exhibe el segundo caso del nuevo par. Esta particularidad consiste en que el agente no logra efectuar un disparo letal en contra de su potencial víctima, porque el disparo no llega a ser ejecutado en lo absoluto, en virtud de alguna circunstancia, enteramente fortuita para el agente, que lo priva de la oportunidad para llegar a efectuar el disparo, a saber: o bien porque este estornuda justamente antes de disponerse a disparar, o bien porque un camión se cruza bloqueando su línea de tiro, o bien porque la potencial víctima entra por una puerta un segundo antes de que pudiera tener lugar el disparo ${ }^{106}$. Respecto de un caso tal, observa Zimmerman, sería adecuado sostener que el agente "habría libremente elegido disparar" contra otro ser humano, "si él hubiese recibido la cooperación de ciertos aspectos del caso" ${ }^{107}$. Esto lleva a que Zimmerman sostenga que la responsabilidad atribuible al agente que fortuitamente no logra estar en posición de efectuar el disparo sería idéntica en grado a la responsabilidad del agente que sí llega a efectuar

102 Zimmerman (2002) pp. 560 ss., quien habla del alcance (scope) y el grado (degree) de la "culpabilidad" (culpability) atribuible a cada agente. Dado que el término "culpabilidad" es usado allí para expresar una categoría moral, y no distintivamente jurídico-penal, parece preferible usar la expresión "responsabilidad".

103 A lo menos, porque la diferencia puede tener impacto ya para la punibilidad del respectivo comportamiento, en la medida en que el sistema jurídico de referencia no haga coextensivos los ámbitos de punibilidad de la consumación y la tentativa, tal como ocurre bajo el CP chileno, cuyo art. $9^{\circ}$ excluye, por defecto, la punibilidad de los hechos punibles constitutivos de faltas que no alcanzan la consumación.

104 Ello se da no solo cuando, como sucede bajo el CP chileno, el delito frustrado y la mera tentativa quedan generalmente asociadas a una reducción de la pena prevista para el correspondiente delito consumado, sino también cuando la ley prevé una rebaja puramente facultativa de pena para el caso de la tentativa (lato sensu).

105 Zimmerman (2002) pp. 563 ss., quien por tal entiende la conjunción de la suerte circunstancial y la suerte constitutiva.

106 Zimmerman (2002) p. 563.

107 Zimmerman (2002) p. 564. 
el disparo letal, pues uno y otro serían responsables en virtud del mismo hecho, a saber, el hecho de ser alguien que habría matado libremente a otro ser humano ${ }^{108}$.

Lo anterior quiere decir que una misma base o fundamento de imputación se satisfaría, por igual, respecto de uno y otro agente. Pero ello ciertamente no impide a Zimmerman reconocer que, bajo ciertas especificaciones ulteriores, en el segundo de los dos casos nada hay de lo cual el agente sea responsable, lo cual equivale a decir que su responsabilidad carece de alcance ${ }^{109}$. Zimmerman cree posible reformular esto último diciendo que aquel resultaría "responsable tout court", lo cual no sería óbice a insistir en el carácter "fundamentalmente relacional" de toda responsabilidad. Pues esto solo exigiría que la responsabilidad en cuestión sea atribuida en virtud de algún hecho que le sirva de base, aun cuando esa responsabilidad pueda no tener objeto de referencia alguno ${ }^{110}$.

Es a lo menos dudoso que, por esta vía, Zimmerman tenga éxito en diluir lo "excesivamente paradójica" que parecería ser la jerga de una responsabilidad carente de objeto (y así de alcance), para así poder sustentar la tesis de la irrelevancia moral del azar circunstancial, en términos tales que, en sentido moral, los agentes involucrados en el segundo par de casos hubieran de merecer exactamente la misma reacción ${ }^{111}$. Pero aquí solo interesa reparar en que la pretendida identidad en el grado de la responsabilidad de uno y otro agente no logra desvirtuar el hecho de que, jurídico-penalmente, en referencia al segundo caso sería suficiente la constatación de que el agente no quedó, bajo su representación de las circunstancias, en situación de poder efectuar un disparo en contra de otro ser humano para descartar, ceteris paribus, la punibilidad de su comportamiento a título de tentativa de homicidio. Y esto es algo que no se ve relativizado en un ápice por el carácter fortuito -esto es, azaroso- de cualquiera haya sido el impedimento para ello.

Es enteramente plausible afirmar, frente a un caso como el recién considerado, que el agente ha sido azarosamente privado de la oportunidad para ejecutar una acción cuya ejecución hubiese podido convertirlo en autor de un homicidio. Pero esto no vale como una razón para pasar por alto que el objeto de una imputación jurídico-penal tiene que ser identificado con un comportamiento susceptible de ser interpretado como el quebrantamiento de una norma cuya aplicabilidad como razón vinculante para ejecutar u omitir acciones de cierta índole depende de la satisfacción de condiciones que especifican la situación en la que habría de ser omitida o ejecutada una acción de esa índole. Si bajo la repre-

\footnotetext{
108 Zimmerman (2002) pp. $564 \mathrm{~s}$.

109 Las especificaciones ulteriores son introducidas por Zimmerman frente a la eventualidad de que se sostuviera que el agente pudiera ser, no obstante lo ya sostenido, responsable o bien de la intención de matar a alguien, o bien de las acciones preparatorias ya ejecutadas; véase Zimmerman (2002) p. 564, nota 30, quien al respecto observa, en lo que aquí interesa, que es perfectamente imaginable que el caso se diera sin que el agente hubiera alcanzado a formarse la intención en cuestión, por un lado, o bien sin que hubiese sido necesario ejecutar acción preparatoria alguna, por otro.

110 Zimmerman (2002) pp. 564 s., 570. Es claro que lo que Zimmerman entiende por el carácter relacional de toda responsabilidad no se ajusta al enfoque triádico elaborado por Duff, según quien sería constitutivo de toda "relación de responsabilidad" que el sujeto responsable lo sea de algo, ante alguien y en virtud de alguna condición o estatus. Véase Duff (2007) pp. 23 ss.; Harel (2011) pp. 103 ss.; también Mañalich (2017b) pp. 176 ss., con referencias ulteriores.

111 Zimmerman (2002) pp. 567 s.
} 
sentación de las circunstancias con la que cuenta un destinatario de la norma respectiva no se configura una situación en la cual esa norma pueda ser prácticamente reconocida como premisa vinculante, la pregunta por su quebrantamiento no resulta pertinente.

\section{BIBLIOGRAFÍA CITADA}

AlCÁCER, Rafael (2001): Tentativa y formas de autoría. Sobre el comienzo de la realización tipica (Madrid, Edisofer).

Anscombe, G.E.M. (1963): Intention (Londres y Cambridge Mass., Harvard University Press).

Beade, Gustavo (2017): Suerte moral, castigo y comunidad (Madrid, Barcelona, Buenos Aires y San Pablo; Marcial Pons).

BeLING, Ernst (1906): Die Lehre vom Verbrechen (Tübingen, J.C.B. Mohr [Paul Siebeck]).

Beling, Ernst (1922): Methodik der Gesetzgebung, insbesondere der Strafgesetzgebung (Berlín y Grunewald, Dr. Walther Rothschild).

Beling, Ernst (1930): Die Lehre vom Tatbestand (Tübingen, J.C.B. Mohr [Paul Siebeck]).

BERZ, Ulrich (1984): "Grundlagen des Versuchsbeginns", Juristische Ausbildung, 1984: pp. 512-519.

Bockelmann, Paul (1957): Strafrechtliche Untersuchungen (Göttingen, Otto Schwarz).

Bratman, Michael (2006): "What is the Accordion Effect?", The Journal of Ethics, 10: pp. 5-19.

BURKHARDT, Björn (1983): "Vorspiegelung von Tatsachen als Vorbereitungshandlung zum Betrug - OLG Karlsruhe, NJW 1982, 59”, Juristische Schulung, 1983: pp. 426-431.

CoHN, Ludwig (1880): Zur Lehre vom versuchten und vollendeten Verbrechen, Tomo I, (Breslau, Wilhelm Koebner).

Danto, Arthur (1973): Analytical Philosophy of Action (Cambridge, Cambridge University Press).

Davidson, Donald (2001): Essays on Actions and Events (Oxford, Oxford University Press, segunda edición).

DolD, Dennis (2017): Eine Revision der Lehre vom Rücktritt vom Versuch (Tübingen, Mohr Siebeck).

Duff, Antony (1996): Criminal Attempts (Oxford, Clarendon Press).

Duff, Antony (2007): Answering for Crime (Oxford y Portland Or., Hart Publishing).

Enoch, David (2010): "Moral Luck and the Law", Philosophy Compass, 5: pp. 42-54.

Feinberg, Joel (1970): Doing \& Deserving (Princeton N.J., Princeton University Press).

FiedLer, Herbert (1967): Vorhaben und Versuch im Strafrecht (Baden-Baden, Nomos).

FincKe, Martin (1975): Das Verhältnis des Allgemeinen zum Besonderen Teil des Strafrechts (Berlín, J. Schweitzer).

Frank, Reinhard (1931): Das Strafgesetzbuch für das Deutsche Reich (Tübingen, J.C.B. Mohr [Paul Siebeck], 18a edición).

Geilen, Gerd (1977): Strafrecht. Allgemeiner Teil (Bochum, Studienverlag Dr. N. Brockmeyer, tercera edición).

Goldman, Alvin (1970): A Theory of Human Action (Engelwood Cliffs N.J., Prentice-Hall).

González Lagier, Daniel (1995): Acción y norma en G.H. von Wright (Madrid, Centro de Estudios Constitucionales). 
Gössel, Karl Heinz (1971): "Zur Strafbarkeit des Versuchs nach dem 2. Strafrechtsreformgesetz”, Goltdammer's Archiv für Strafrecht, 1971: pp. 225-236.

Hacker, P.M.S. (2007): Human Nature: The Categorical Framework (Malden, Oxford y Chichester; Wiley-Blackwell).

Harel, Alon (2011): “The Triadic Relational Structure of Responsibility: A Defence”, en Cruft, R., Kramer, M. y Reiff, M. (eds.), Crime, Punishment and Responsibility. The Jurisprudence of Antony Duff(Oxford, Oxford University Press) pp. 103-121.

Heintschel-Heinegg, Bernd von (1997): "Versuch und Rücktritt", Zeitschrift für die gesamte Strafrechtswissenschaft, 109: pp. 29-57.

Hilpinen, Risto (2016): "Las acciones como transformaciones de estado en G.H. von Wright”, DOXA, 39: pp. 49-63.

KindHÄUSER, Urs (1980): “Basis-Handlungen”, Rechtstheorie, 11: pp. 479-95.

KindHÄUSER, Urs (1989): Gefährdung als Straftat (Frankfurt a.M., Vittorio Klostermann).

KindhäUser, Urs (2011): "Zum strafrechtlichen Handlungsbegriff”, en Paeffgen, H.-U. et al. (coords.), Strafrechtswissenschaft als Analyse und Konstruktion. Festschrift für Ingeborg Puppe zum 70 Geburtstag (Berlín, Duncker \& Humblot) pp. 39-63.

KIndHÄUSER, Urs, 2018: "Versuch und Vollendung - normtheoretisch betrachtet", en Barton, Stephan et al. (coords.), Festschrift für Thomas Fischer (Múnich, C.H. Beck) pp. 125-141.

KratzsCh, Dietrich (1983): "Die Bemühungen um Präzisierung der Ansatzformel (§ 22 StGB) - ein absolut untauglicher Versuch (Teil 1)?”, Juristische Arbeitsblätter, 1983: pp. 420-429.

KüHL, Kristian (1979): “Grundfälle zu Vorbereitung, Versuch, Vollendung und Beendigung”, Juristische Schulung, 1979: pp. 718-721, 874-877.

KüHL, Kristian (1980): "Grundfälle zu Vorbereitung, Versuch, Vollendung und Beendigung”, Juristische Schulung, 1980: pp. 120-126, 273-276, 506-510, 650-654, 811-815.

KÜPER, Wilfried (1992): “,Teilverwirklichung' des Tatbestandes: ein Kriterium des Versuchs?", Juristenzeitung, 1992: pp. 338-347.

Maier, Thomas, 2005: Die Objektivierung des Versuchsunrechts (Berlín, Duncker \& Humblot).

Malamud, Jaime (2008): Suerte, acción y responsabilidad: un ensayo sobre suerte, moralidad y castigo (Bogotá, Editorial Universidad del Rosario).

Mañalich, Juan Pablo (2012): "El concepto de acción y el lenguaje de la imputación", DOXA, 35: pp. 663-690.

Mañalich, Juan Pablo (2014): Norma, causalidad y acción (Madrid, Barcelona, Buenos Aires y San Pablo; Marcial Pons).

Mañalich, Juan Pablo (2017a): "La tentativa como hecho punible. Una aproximación analítica”, Revista Chilena de Derecho, 44(2): pp. 461-493.

MaÑAlich, Juan Pablo (2017b): "Responsabilidad, autoridad y democracia. Una exploración crítica de la filosofía del derecho penal de Antony Duff”, Discusiones, XVII: pp. 167-219.

Mañalich, Juan Pablo (2018): "Norma, acción y deber: el modelo del silogismo práctico", en González Lagier, D. y Figueroa, S. (eds.), Libertad, razón y normatividad (Palestra, Lima) pp. 89-122. 
Mañalich, Juan Pablo (2019a): "Tentativa, error y dolo. Una reformulación normológica de la distinción entre tentativa y delito putativo", Política Criminal, 14(27): pp. 296-375.

MaÑalich, Juan Pablo (2019b): "Tentativa y resolución-al-hecho. Una reconstrucción desde la filosofía de la acción” (de próxima publicación en Isonomía).

Murmann, Uwe (1999): Versuchsunrecht und Rücktritt (Heidelberg, C.F. Müller).

Nagel, Thomas (1979): Mortal Questions (Cambridge, Cambridge University Press).

Olave, Alejandra (2018): "El delito de hurto como tipo de delito de resultado", Política Criminal, 13(25): pp. 175-207.

Roxin, Claus, (2003): Strafrecht Allgemeiner Teil, Tomo II (Múnich, C.H. Beck).

RudolPHI, Hans-Joachim (1973): "Zur Abgrenzung zwischen Vorbereitung und Versuch OLG Celle, NJW 1972, 1823”, Juristische Schulung, 1973: pp. 20-25.

SAFFERLING, Christoph (2006): "Die Abgrenzung zwischen strafloser Vorbereitung und strafbarem Versuch im deutschen, europäischen und im Völkerstrafrecht", Zeitschrift für die gesamte Strafrechtswissenschaft, 118: pp. 682-716.

Searle, John, 2010: Making the Social World (Oxford y Nueva York, Oxford University Press).

Sosa, Ernst (1965): "Actions and their Results", Logique \& Analyse, 8(30): pp. 111-125.

Stoutland, Frederick (1968): "Basic Actions and Causality", The Journal of Philosophy, 65: pp. 467-475.

Tiedemann, Klaus (1992): “Zum Verhältnis von Allgemeinem und Besonderem Teil des Strafrechts”, en ARzT, G. et al. (coords.), Festschrift für Jürgen Baumann (Bielefeld, Ernst und Werner Gieseking) pp. 7-20.

Vogel, Joachim (1993): Norm und Pflicht bei den unechten Unterlassungsdelikten (Berlín, Duncker \& Humblot).

Vogler, Theo (1985): “§ 22”, en Jescheck, Hans-Heinrich, Russ, Wolfgang y Wills, Günther (coords.), Strafgesetzbuch Leipziger Kommentar (Berlín y Nueva York, Walter de Gruyter, $10^{a}$ edición).

Vogler, Theo (1993): “Der Beginn des Versuchs", en KüPER, Wilfried y Welp, Jürgen (coords.), Beiträge zur Rechtswissenschaft. Festschrift für Walter Stree und Johannes Wessels zum 70. Geburtstag (Heidelberg, C.F. Müller) pp. 285-303.

Von Gemmingen, Hans Dieter (1932): Die Rechtswidrigkeit des Versuchs (Breslau-Neukirch, Alfred Kurtze).

Von Hippel, Reinhard (1966): Untersuchungen über den Rücktritt vom Versuch (Berlín, Walter de Gruyter).

Von Hippel, Robert (1930): Deutsches Strafrecht, tomo II (Berlín, Springer).

Von Wright, Georg Henrik (1963): Norm and Action (Londres, Routledge \& Kegan Paul).

Zimmerman, Michael (2002): “Tacking Luck Seriously”, The Journal of Philosophy, 99: pp. 553-576.

\section{JURISPRUDENCIA CITADA}

BGH 1 StR 264/75, 16 de septiembre de 1975, en: BGH 26, 201.

BGH 1 StR 703/79, 4 de diciembre de 1979.

OLG Karlsruhe, 12 de agosto de 1981 - 3 Ss 167/81, en: NJW 198259. 